\title{
Forms and functions of vague language in academic journal article abstracts
}

\author{
Gabriela Cusen* \\ Faculty of Letters, "Transilvania" University of Braşov, Bd. Eroilor 29, 500036 Braşov, Romania
}

\begin{abstract}
Article info
History:

Received September 5, 2018

Accepted October 3, 2018

Published May 7, 2019

Key words:

academic journal abstracts

vague language

IMRaD moves

Abstract

This paper reports on an exploratory investigation of the IMRaD moves (Introduction, Method, Results and Discussion) which show the degree of informativeness in terms of referential explicitness of academic texts and of use of vague language in academic journal abstracts published in 2010 and 2011. The areas of research these articles focus on are: language and linguistics, literature and cultural studies. The analysis of the data, based on an existing analytical framework (Cutting, 2012), revealed that authors use vague language (e.g.: 'general nouns', 'hedging devices' and 'vague quantifiers') and that the abstracts mostly consist of the introduction and discussion moves. Results of research into the writing of article abstracts may benefit both novice academic text writers and academics guiding their work.
\end{abstract}

\section{Introduction}

When academics decide to publish their research articles in scientific journals, they need to write abstracts for their work and abide by the instructions of the editors in so doing. This paper reports on an exploratory study of abstracts for articles published in English in an academic journal- "Bulletin of Transilvania University of Brașov", Romania - to identify forms and functions of vague language used by authors and also to discuss the genre of academic journal article abstracts (AJAs) in terms of IMRaD moves. There are two major parts of this work, i.e., first there is a review of work on vague language from a both theoretical and research perspective (see for example, Channell, 1994; Drave, 2001; Cutting, 2007, 2012) followed by a description of what Cutting (2012, p. 283) calls "the distribution of IMRaD moves (Introduction, Method, Results and Discussion)" which the abstracts in the corpus may or may not contain. Second, the aforementioned theoretical perspective was needed in order to set up an analytical framework to be used in the examination of the journal article abstract data corpus.

\section{Vague Language (VL): definitions}

Starting from the well-known truth that "[a]ny social group sharing interests and knowledge employs non-specificity in talking about their shared interest" (p. 193), Channell (1994) states that an expression or word is vague if:

a) it can be contrasted with another word or expression which appears to render the same proposition;

b) it is purposely and unabashedly vague or

c) the meaning arises from intrinsic uncertainty (1994, p. 20).

In the same line of thought, for Cutting (2012, p. 284), vague language is represented by "forms that are intentionally fuzzy, general, and imprecise, (...) and are heavily dependent on shared contextual knowledge for their meaning".

When it comes to examining vague language in more detail, some authors, for example Channell (1994, p. 78, 119, 157), have a rather restrictive view of VL and limit its use to 'approximating quantities',

\footnotetext{
*Email address: gabriela.cusen@unitbv.ro.
} 
'referring vaguely to categories' and 'placeholder words' such as 'thingy' or 'whatshisname. Other authors, notably Brown \& Levinson (1987, p. 116), take a much less restrictive position and include hedges such as 'I think' in the category of vague language. From the perspective of what he calls a 'more inclusive approach', Trappes-Lomax (2007, p. 122) views

(...) an instance of VL [as] any purposive choice of language designed to make the degree of accuracy, preciseness, certainty or clarity with which a referent or situation (event, state, process) is described less than it might have been.

What most definitions of VL seem to have in common is the idea of purposeful choice of imprecision by language users and their ability to rely mostly on shared knowledge of context in order to convey their thoughts to their interlocutor, be that a reader or a listener.

\section{Vague Language (VL) in academic writing: forms and functions}

Since the study reported here focuses on the examination of AJAs, this discussion is only of those VL forms and functions which the literature relates to this type of text. Thus, according to Cutting (2012, p. 284), researchers in the area of VL studies focusing on written academic English have been mainly "concerned with vague quantifiers and hedging devices; general nouns and general extenders have received some attention; general verbs and indefinite pronouns have received less".

This section deals with only the categories of vague quantifiers, hedging devices and general nouns from the perspective of various specialists in the field since these were identified in the data examined in this study. Further in this paper, these categories and their functions are exemplified and discussed.

In the works of Channell (1994), Kennedy (1987), Ruzaite (2004, 2007), vague quantifiers are presented as generally used as a 'matter of convenience' when the writer considers that more precision is unnecessary. Examples of this type of vague language could be: about 10 subjects, around 100 questionnaires, plenty of time, a large number of samples. The next category, that of hedging devices is seen by Cutting (2012, p. 285) as a means used by writers to show their "commitment to the truth value of their proposition". The author gives these examples for hedging devices: "catenatives (verbs taking non-finite complements, such as appear to, (...)), modal operators (might), and modal nouns (probability), adjectives (likely) or adverbs (possibly)" and she traces them in the work of Hyland (1996) and Salager-Meyer (1994). Finally here, while Halliday \& Hasan (1989) consider general nouns to be "dummy' nouns such as thing, people and place", Mahlberg (2005) claims they are "high-frequency nouns that extract their meaning from local textual functions or co-text". Cutting's (2012) examples of such general nouns are: feature (s), factor(s), issue(s), etc.

A review of literature on VL suggested that it is used in academic texts such as the journal abstracts analysed here with both hedging and non-hedging functions. Salager-Meyer (1994), Banks (1998), Drave (2001), Trappes-Lomax (2007) and Cutting (2012) discuss three hedging and four non-hedging functions of VL. The three hedging functions mentioned above are courtesy, modesty and caution and they are particularly relevant for the categories of VL identified in the data in this study.

The first hedging function, that of 'courtesy', is often identified as a reason for using VL. Authors therefore tend to use VL out of 'courtesy' since sometimes their assertions show that, in the words of TrappesLomax (2007, p. 131), they do so out of "respect for the assumed prior knowledge of the audience" and what they appear to imply may be "I could be more explicit but you might feel insulted that I'm spelling it out". When it comes to categories of VL, Banks $(1998$, p. 17) notes that the use of vague quantifiers is a 'basically interpersonal' hedging function showing that the writer "is conforming to expected style, or avoiding face-threatening behaviour".

Second, the function of 'modesty' may originate in the authors' preference for hedging by using VL which lacks precision even if they are certain of their assertions. This is apparently so because they find it necessary to "display humility in order to minimise the threat to their own face" (Cutting, 2012, p. 285). 
In this case, Salager-Meyer (1994, p. 149) notes that since "argumental arrogance and exuberance are not well seen by the scientific community", the writer of an academic text uses VL to say "I could be more explicit but I don't want to boast".

And third, the hedging function of 'caution' shows that the use of VL is tentative because the authors are in a way worried about possible inconclusive findings in their studies. This may be the case when hedging is "the strongest claim a careful researcher can make" (Salager-Meyer, 1994, p. 151) and thus the use of VL shows "scientific scepticism and doubt". According to Cutting (2012, p. 286), 'caution' "amounts to [the] author saying 'I can't be more explicit because I'm not sure if I'm right". This hedging function is considered relevant in the case of the AJAs examined here since the use of cautionary language may be an advantage for the writers when the work they report on is incomplete.

The authors whose work on the functions of VL was cited above state that writers of academic texts also use it for reasons which are not related to hedging. These authors examine four non-hedging functions which they name: convenience, self-defence, power and anticipation. The non-hedging function of 'convenience' may be used by authors possibly because they consider that precision may not give substantial strength to their argument. In this respect, Ruzaite (2004, p. 217-239) claims that the VL category of vague quantifiers is used when writers feel that precision is 'unnecessary' and they might be thinking "I could be more explicit, but it would be irrelevant to the point that I am making”. In the case of AJAs this may be a relevant function due to the word number constraints for abstracts imposed by the publisher.

When VL is used for 'self-defence', Trappes-Lomax (2007, p. 122-123) shows that the writers "avoid precision in order to minimise the threat to their own face". He also states that users of VL in academic contexts do so because they feel the need to withhold information in order to prevent being challenged by the scientific community or to "protect themselves from intellectual property theft". Similarly, Ruzaite (2007, p. 231) investigated the use of VL by students and teachers and found that they used vague quantifiers " to shield their claims against possible criticism". She also explains that in this situation users of VL for self-defence may be thinking "I can't be more explicit because I don't know any more".

Use of VL to exert 'power' is a function which is quite the opposite of hedging. The work of Fairclough (1989, p. 82-83) is well-known for the investigation of the relationship between language and power. One of the relevant points that he makes is that texts exert an influence over the reader because they "impose implicit assumptions upon the audience" and therefore encourage them to interpret these texts by starting from the same assumptions. For Cutting (2012, p. 286) use of VL for 'power' in academic texts shows the writer's claim for membership of a scientific community and in order to persuade their readers they might imply "You can see I'm an insider from my use of implicit references (...)".

The last of the non-hedging functions is 'anticipation'; it seems to fit well with what Cutting (2012, p. 286) calls 'the promissory nature' of AJAs in the case of the study reported here. She states that the author of an abstract "may prefer not to talk in detail about their results because they do not want to give away the denouement of their study; they wish to rouse the curiosity" of the reader leafing through an academic journal.

The following section of this paper is a review of literature on IMRaD moves meant to give the analysis of the data in this study a second perspective, i.e. that of the degree of informativeness of academic journal abstracts.

\section{IMRaD moves in academic journal abstracts (AJAs)}

Many of the authors conducting research in the domain of the writing of academic text abstracts (e.g. Halleck \& Connor, 2006; Swales \& Feak, 2009; Cutting, 2012) have mainly focused on scientific conference abstracts and directed their attention towards 'moves' that are known as IMRaD, i.e. introduction, method, results and discussion moves. As a first 'move', the Introduction is generally understood to present, in Cutting's (2012, p. 284) words, "the context, the aims [of the study] and the literature review" or, due to word number constraints, a mere placing of the study in the scientific field it belongs to. The Method move 
is the one that involves an explanation of how the data for the study were both collected and analysed. In the 'results' section of the abstract the author summarises the findings of the study. The final move, 'discussion', gives the author the chance to interpret the findings of the study and also to give an indication of its 'implications and applications'.

Studies of conference abstracts such as the ones reported in the works of previously mentioned authors have demonstrated that the IMRaD structure of these texts is both taken into account by reviewers and appears to affect their rating prior to acceptance of conference presentations. It also seems worth mentioning that the findings of these studies demonstrate that in the conference abstracts they focused on all the IMRaD moves were not necessarily present and the researchers did not decide which of them were essential. For example, Kaplan et al. (1994) conducted a study whose quantitative findings showed that even though all the abstracts in their corpus contained a 'results' move, almost half of them were rejected by the reviewers before a conference. In her more recent study, Cutting (2012) found that in half of the conference abstracts she investigated "the authors had not completed the analysis and some had not finished collecting their data, and that the abstracts mostly consisted of introduction and method moves". The other important result of these studies shows that all authors of conference abstracts use vague language represented primarily by general nouns whose function was deemed to be either 'convenience' or 'anticipation'.

To my knowledge, a similar investigation of AJAs is rather new in the filed. However, that such an investigation should lead to conclusions that are similar to the ones based on conference abstracts seems highly likely since both types of abstracts pertain to the area of academic writing.

In summary, there seems to be little consensus among the representatives of the literature on the observance of IMRaD moves in abstracts of academic papers and the findings of studies on the use of $\mathrm{VL}$ in such texts give it only a role related to cohesion and hedging. In order to investigate the IMRaD moves and use of VL in a small corpus of academic journal article abstracts, a discussion of these texts based on an adaptation of Cutting's (2012) analytical framework is detailed in the following sections. This is preceded by a description of the corpus.

\section{Method}

The two subsections below deal with the description and analysis of the data corpus. The examples from the data are discussed in view of answering the two research questions in subsection 5.2.

\subsection{Data in this study}

The data corpus for this exploratory study consists of 62 academic journal article abstracts published between 2010-2011 in the "Bulletin of Transilvania University of Brașov", Romania, Series IV, Issue 1 (2010) and Issues 1 and 2 (2011): Philology and Cultural Studies. 26 abstracts belonging to the domain of Language and Linguistics (L\&L) (between 40 and 255 words in length) and 2 abstracts for articles focusing on Literature (L) (between 60 and 109 words) were collected from the issue of the 2010 Bulletin. There were no articles on Cultural Studies (CS) in this issue. Since 2011, the issuing frequency of the Bulletin has been biannual, and thus this year's two issues contain 13 article abstracts on Language and Linguistics (L\&L) (between 49 and 130 words in length), 14 abstracts on Literature topics (L) (between 53 and 174 words in length), and 7 abstracts on Cultural Studies (CS) (between 76 and 187 words in length). The AJAs themselves were then collated in one corpus. They are anonymous in the sense that the title of the articles, the names of the authors and their academic affiliation are not of interest for this study. However, mention need be made that although all the articles and their abstracts are written in English since this is the main language of the journal, the authors are native speakers of Romanian.

In order to give an indication of what the editorial board of the journal require in terms of the writing of article abstracts, below is an extract from the Instructions for authors meant to guide the writing of 
abstracts ("Bulletin of Transilvania University of Braşov" - Instructions for authors ${ }^{1}$ ):

The abstract should synthetically outline all the pertinent results, in a short but intelligible form. The abstract should begin through clearly stating the purpose of the paper and should end by formulating the most important conclusions. There will be used short, direct and complete sentences, written in a single paragraph, without tabs. The abstract will be written with Times New Roman 10 pt and will have $7 . . .10$ lines.

\subsection{Data analysis and discussion}

The analysis of the data was guided by the following questions: 1 . What are the forms of VL in the corpus and what is their function? and 2. What are the functions of the VL forms present in the IMRaD moves in the corpus?

While question 1 above was meant to direct the researcher's attention to the forms of VL categories identified in the data, the role of the second was to help with the understanding of the relationship between the functions of VL forms and their presence in the IMRaD moves of the AJAs.

The process of analysing the abstracts consisted of two steps. First, the texts were manually tagged in order to identify lexical and grammatical categories. During this stage of the analysis it became clear that the categories of VL most used in the abstracts were vague quantifiers, hedging devices and general nouns. Second, the IMRaD moves in the abstracts were also identified manually on the basis of those described by Cutting (2012) and labelled as follows: (i) Introduction: context, aims and literature review = [Intr.]; (ii) Method: data collection and analysis = [Meth.]; (iii) Results: findings = [Res.]; (iv) Discussion: explanations, implications and applications $=[$ Disc. $]$.

Abstract excerpts which contain examples of the three categories of VL identified in the data (vague quantifiers, hedging devices and general nouns) followed by full abstracts whose IMRaD structure is analysed are cited and discussed below.

(1) Which choice is to be considered adequate is to be discussed on the basis of several theoretical points of view appropriate to the field of translation criticism. (L\&L)

(2) Although at the beginning of the $21^{\text {st }}$ century a part of the population favours a republic, the monarchy is still strong, with the head of state following the motto "All for Norway" ("Alt for Norge") (CS)

(3) To this aim I have chosen an article from a Romanian satirical newspaper, Academia Catavencu, which I found particularly interesting in that it poses a number of problems for the analysis. $(\mathrm{L} \& \mathrm{~L})$

Examples (1), (2), and (3) above come from two Language and linguistics (L\&L) abstracts and one from a Cultural Studies (CS) abstract. However, mention must be made that the analysis of the data showed that in this corpus there were very few such instances of use of vague quantifiers or 'non-numerical vague quantifiers' as Channell (1994, p. 95) calls them. The three constructions italicized in the examples above (several, a part of, a number of), can also be categorized in terms of their meaning according to Channell's framework. Thus, all three of them could be considered 'neutral with respect to quantity' $(1994$, p. 95). The function of such VL was considered to be either 'convenience' (Cutting, 2012) which is a non-hedging function showing that authors may use VL to mean that further precision would not contribute to their arguments, or 'caution', which is a hedging function leading to the conclusion that the authors express tentativeness about inconclusive data and honestly convey scepticism and doubt.

(4) By presenting Arghezi as an exemplary role model, Caraion creates the opportunity to use whatever resemblance might exist between them to transform the justification of Arghezi's actions into an indirect self justification for his own options. (L)

\footnotetext{
${ }^{1}$ http://webbut.unitbv.ro/Bulletin/Series\%20IV/RO/Instructiuni.html.
} 
(5) The comparative method is possibly a suitable choice since simultaneous representation is mostly profitable for a balanced attitude to interpreting both the agent and the object, be them the victim and the aggressors or the offenders and the policemen. (L\&L)

In examples (4) and (5), the hedging devices (might - a modal operator and possibly - a modal adverb) are used to qualify authors' commitment to the truth-value of their claims. The function of this type of VL is both 'modesty' meaning that the authors prefer to hedge in order to show humility and to minimize the threat to their own face and 'caution' showing that the authors are 'careful researchers' and honestly express scientific scepticism and doubt.

(6) Here, irony is not considered a simple comment or utterance, but also consists of a complex communicative interaction influenced by different factors. (L\&L)

(7) Following Stanley Fish's argument that theory as theory can have no consequences, this article suggests that by focusing on other aspects of theory we can both understand that its death is not a recent episode and that its power may actually reside in its problematic core'. (L)

Examples (6) and (7) show use of vague general nouns (different factors and other aspects of theory-in this case, noun phrases whose centre is represented by vague general nouns) and they come from Language and Linguistics (L\&L) and Literature (L) abstracts. In example (6) (and in most of the corpus), the prehead modifier simply limits the category of meaning, the noun remaining relatively vague. Readers have to conclude from the co-text what these factors are. Here the function may be 'convenience' or 'anticipation'. Example (7) shows the use of a general noun which has both a pre-head and a post-head modifier. The latter, according to Mahlberg (2005), can be equated to partitives with a support function. Importantly, the authors of all abstracts in this corpus used general nouns in similar ways.

(8) [Intro] The paper analyzes the importance of certain stylistic aspects while translating the German tense "episches Präteritum" into Romanian. [Meth] The translation criticism is carried out on Süskind's novel "The Perfume". The paper focuses on the difficulties on rendering the same stylistic values of the epic narration into Romanian. [Results] The difficulties arise, because in German there is only one single tense for narration, the so called epic past tense, while in Romanian the translator has three choices-the tenses "perfect compus", "perfect simplu" and "imperfect". [Disc] Which choice is to be considered adequate is to be discussed on the basis of several theoretical points of view appropriate to the field of translation criticism. (L\&L)

(9) [Intro] The present paper intends to apply the fencing game model of irony proposed by Anolli, Infantino and Ciceri (2001). [Meth] The research consists in the comparative approach of some ironical devices from parliamentary debates in Romanian and British politics since 2008 until present. [Intro: aim] The aim of the article is to analyse how irony is accomplished in interaction, namely construction and usage. [Disc] Irony is easily recognisable and it is used as a criticism and as an attack. [Res] Here, irony is not considered a simple comment or utterance, but also consists of a complex communicative interaction influenced by different factors. (L\&L)

(10) [Intro] The fact that literary theory may have exhausted its resources is already common knowledge. Following Stanley Fish's argument that theory as theory might have no consequences, this article suggests that by focusing on other aspects of theory we can both understand that its death is not a recent episode and that its power may actually reside in its problematic core. (L)

Examples (8), (9) and (10) above are abstracts of articles belonging to all three areas of the journal mentioned in the introduction. They are discussed below both in terms of the authors' use of VL and in relation to their IMRaD structure. In these examples, the abbreviations for the research areas are in round brackets: $(\mathrm{L} \& \mathrm{~L}),(\mathrm{L})$ and $(\mathrm{CS})$. The IMRaD moves identified in the examples are signalled in square brackets. 
First then, the way authors of abstracts use VL, its forms and possible functions was discussed above. However, this needs elaboration in relation to the presence of VL in the IMRaD moves in the abstracts. Thus, vague quantifiers such as several in example (8), hedging devices such might in example (10) and general nouns such as factors or aspects with pre- and/or post-head modifiers in examples (9) and (10) were identified mostly in the 'introduction' and 'discussion' moves of the abstracts with the occasional use in the 'method' move. This may be because the authors either leave it to the readers to conclude on the meaning from the co-text or because they invite the reader to find answers in the full text of the article.

Second, as anticipated, based on the findings of Halleck \& Connor (2006) and Cutting (2012), the IMRaD structure of the AJAs did not have an equal distribution of moves. A quantitative discussion may seem less relevant for the small corpus of this study. Nevertheless, that only 2 abstracts, whose topics belong to the area of language and linguistics, of the 62 in the corpus consisted of all 4 moves may be worth taking into account. It also seems interesting and again worth taking into account in similar further research that, irrespective of their research area, the structure of 11 abstracts shows only three moves (introduction, method and discussion), 25 abstracts only two moves (Introduction and method/discussion) and 24 abstracts consist of only the introduction without any indication of method, results or discussion. Example (8) above is one of the two whose structure contains all four IMRaD moves the literature focuses on. Examples (9) and (10) are representative for the abstract corpus in that they either have a move structure which may be confusing for the reader because authors tend to go back and forth between the moves as in (9) or the abstracts consist of only the introduction move as in (10).

\section{Conclusion: RQs revisited}

In answer to the questions that have guided the analysis of the data corpus, it seems clear that the AJAs mainly consisted of 'introduction' and 'discussion' IMRaD moves; 'method' and 'results' moves were not frequent. The vague language forms in these moves were mostly general nouns [e.g.: activity (-ies), element (s), emphasis, issue(s) perspective(s), problem(s)] whose pre-head modifiers that did not add much meaning (e.g.: new perspectives, special emphasis, optimal strategies, complex activity). Moreover, in addition to the function of textual cohesion general nouns fulfilled hedging ('courtesy', 'caution') and non-hedging ('convenience', 'anticipation', and 'self-defence') functions.

However, since this study is of an exploratory nature, the conclusions from such a small corpus are by no means generalizable. Moreover, the data analysed in this study were drawn from areas of language and literary study only, which may give it a limited external validity. On a more positive note, it may be that results of such research into the writing of article abstracts will benefit both novice academic text writers and academics guiding their work.

The findings of this exploratory study may lead more extensive work in the same line and data (abstracts) from other research areas (engineering, medicine, business, etc.) could be collected in a much larger corpus meant to help explore how their IMRaD moves and use of VL differ from those focusing on language, literature or cultural studies.

\section{Bibliography}

Banks, D. (1998). Vague Quantification in the Scientific Journal Article, in “ASp, la Revue du GERAS”, 19-22, p. 17-27, Crossref.

Brown, P. \& Levinson, S. C. (1987). Politeness: Some universals in language usage, Cambridge University Press, Cambridge. Channell, J. (1994). Vague Language, Oxford University Press, Oxford.

Cutting, J. (ed.) (2007). Vague Language Explored, Palgrave Macmillan, New York, Crossref.

Cutting, J. (2012). Vague Language in Conference Abstracts, in "Journal of English for Academic Purposes", vol. 11, iss. 4, p. 283293, Crossref

Drave, N. (2001). Vaguely Speaking: A corpus Approach to Vague Language in Intercultural Conversations, in Peters, P., Collins, P. \& Cohen, A.S. (eds), New Frontiers of Corpus Research, p. 25-40, Crossref.

Fairclough, N. (1989). Language and Power, Longman, London. 
Halleck, G. B. \& Connor, U.M. (2006). Rhetorical Moves in TESOL Conference Proposals, in "Journal of English for Academic Proposals", vol. 5, iss. 1, p. 70-86, Crossref.

Halliday, M. A. K. \& Hasan, R. (1976). Cohesion in English, Longman, London.

Hyland, K. (1996). Talking to the Academy: Forms of Hedging in Science Research Articles, in "Written Communication", vol. 13, iss. 2, p. 251-281, Crossref.

Kaplan, R. B. et al. (1994). On abstract writing, in “Text”, vol. 14, iss. 3, p. 401-426, Crossref.

Kennedy, G.D. (1987). Quantification and the Use of English: A Case Study of One Aspect of the Learner's Task, in "Applied Linguistics", vol. 8, iss. 3, p. 264-286, Crossref.

Mahlberg, M. (2005). English General Nouns: A Corpus Theoretical Approach, John Benjamins Publishing Company, Amsterdam, Crossref.

Ruzaite, J. (2004). Academic Precision Reconsidered: A Corpus-Based Account, in "SKY Journal of Linguistics", vol. 17, p. 217247, [online].

Ruzaite, J. (2007). Vague Language in Educational Settings: Quantifiers and Approximators in British and American English, Peter Lang, Frankfurt am Main.

Salager-Meyer, F. (1994). Hedges and Textual Communicative Function in Medical English Written Discourse, in "English for Specific Purposes", vol. 13, iss. 2, p. 149-170, Crossref.

Swales, J.M. \& Feak, C.B. (2009). Abstracts and the Writing of Abstracts, University of Michigan Press, Michigan, Crossref.

Trappes-Lomax, H. (2007). Vague language as a means of self-protective avoidance: Tension management in conference talks, in Cutting, J. (ed.), Vague Language Explored, p. 117-137, Palgrave Macmillan, New York, Crossref. 